Vietnam Journal of Mechanics, VAST, Vol. 26, 2004, No.1 (31 - 38)

\title{
A NUMERICAL MODEL FOR WATER-OIL FLOW IN NATURALLY FRACTURED RESERVOIRS
}

\author{
Ha Ngoc Hien, Nguyen Van Diep and Duong Ngoc Hai \\ Institute of Mechanics, VAST, 264 Doi Can, Hanoi, Vietnam
}

\begin{abstract}
This paper describes the development of a three-dimensional, two-phase model for simulating the flow of water and oil in naturally fractured reservoirs. The model is based on the dual porosity approach. Main flow in the reservoir occurs within the fractures with local exchange of fluids between the fracture system and matrix blocks. A new formula for matrix/fracture fluid exchange rate is proposed based on an extension of the equation developed by Kazemi to account the gravity effects. This formula allows to eliminate the matrix pressure in the pressure equation for fractures and makes the solution algorithm easier.

Some example calculations are presented to validate the model. These include a comparison of the results of this paper with previous results, showing the gravity effects and applicability of the model for field-scale problems.
\end{abstract}

\section{Introduction}

Fractured reservoir models were developed to simulate fluid flow in a system of continuous fractures of high permeability and low porosity that surround porous, oil-saturated matrix blocks of much lower permeability but higher porosity. The main difference between flow in fractured medium and flows in conventional porous system is that, in the fractured medium, the interconnected fracture network provides the main path for fluid flow through the reservoir, while local flows (exchanges of fluid) occur between the matrix blocks and the surrounding fractures. Matrix oil flows into the fractures, and the fractures carry the oil to the wellbore.

Most of fractured reservoir models are constructed based on the dual porosity approach. The reservoir is considered as two overlying continua, the matrices and the fractures, in which the flow is governed by Darcy's law. The main problem is to model the flow exchanges between the matrices and the fractures. For single-phase flow, Barenblatt et al. [1] considered the matrix-fracture flow as a source function resulting from pressure difference:

$$
\left(q_{s}\right)_{m f}=-\left(\frac{k}{\mu B}\right)_{m} \sigma\left(p_{m}-p_{f}\right)
$$

where $\left(q_{s}\right)_{m f}$ - matrix-fracture flow rate per unit volume; $p_{m}, p_{f}$ - matrix and fracture pressures, $k$ - matrix permeability, $\mu, B$ - viscosity and volume formation factor of the fluid; and $\sigma$ - the shape factor depending on the matrix block geometry. 
By extending the single-phase equation (1.1), Kazemi et al. [2] presented a water-oil model in which the transfer rate is calculated as following:

$$
\left(q_{s}\right)_{\alpha m f}=-\sigma\left(\frac{k k_{r a}}{\mu_{\alpha} B_{\alpha}}\right)_{m}\left(p_{\alpha m}-p_{\alpha f}\right),
$$

where $\alpha=w$ or 0 (water or oil) is phase index, $k_{r \alpha}$ - phase relative permeability, and

$$
\sigma=\frac{4}{1 / a^{2}+1 / b^{2}+1 / c^{2}}
$$

where $a, b$ and $c$ are the characteristic matrix dimensions in different space directions.

Physically, equation (1.2) states that the total transfer of each phase throughout of each matrix block face is independent of the orientation of this face. Thus the gravity effects that act in only one vertical direction are ignored. This model therefore assumes that oil is recovered from the matrix block only by capillary imbibition of water, by the pressure difference between the matrix blocks and surrounding fractures, and by fluid expansion. The model is applicable for highly fractured reservoirs with small matrix blocks of low permeability, in which the oil recovery from matrix blocks by gravity is negligible. To account the gravity effects, Kazemi and Gilman [3] proposed a model that adds a gravity term in equation (1.2) by considering that the matrix blocks and fractures are at different depths within the model cells. This approximation is valid mainly when gravity is the dominant mechanism of oil recovery from matrix blocks. Several other attempts have been made to include gravity, for example, by Gilman (1986) [4] by subgriding the matrix blocks, or by Quandalle \& Sabathier (1987) [5] by calculating the flow exchange on six faces of matrix block. These models are rather very complicated and require much more computing costs.

In this paper an extension of formula (1.2) is proposed by adding a gravitational term which is easily calculated from the average fluids density between the matrix blocks and fractures and the matrix block height. The new formula allows also to construct a rather simple algorithm based on IMPES technique to solve the problem. A numerical code have been developed based on this algorithm. The calculated results are compared to the results of others. The code is also applied for a field problem of Dragon reservoir. For the field problem, the results are compared to field data and the results obtained by the commercial reservoir simulator IMEX of CMG.

\section{Mathematical Model}

\subsection{Flow equations}

Assuming that the flow of each phase satisfies the Darcy's filtration law, the reservoir is discretized into an uniform grid with grid dimensions $\Delta x, \Delta y, \Delta z$. The finite-difference equations for two-phase (oil/water) flow are following.

For fractures,

$$
\Delta\left[T_{\alpha f}\left(\Delta p_{\alpha f}-\gamma_{\alpha f} \Delta D_{f}\right)\right]-q_{\alpha m f}=\frac{V}{\Delta t} \Delta_{t}\left(\frac{\phi S_{\alpha}}{B_{\alpha}}\right)_{f}+q_{\alpha} .
$$


For matrix

$$
\Delta\left[T_{\alpha m}\left(\Delta p_{\alpha m}-\gamma_{\alpha m} \Delta D_{m}\right)\right]+q_{\alpha m f}=\frac{V}{\Delta t} \Delta_{t}\left(\frac{\phi S_{\alpha}}{B_{\alpha}}\right)_{m},
$$

where $\Delta, \Delta_{t}$ are finite-difference operators, $V=\Delta x \Delta y \Delta z, S_{\alpha}$ is phase saturation, $\phi$ porosity, $q_{\alpha m f}=V\left(q_{s}\right)_{\alpha m f}$ is matrix-fracture flow rate for phase $\alpha$.

The transmissibility $T_{\alpha f x}$ in $x$ direction is defined by:

$$
T_{\alpha f x}=\left(\frac{k k_{r \alpha} \phi}{\mu_{\alpha} B_{\alpha}}\right)\left(\frac{\Delta y \Delta z}{\Delta x}\right) \text {. }
$$

The transmissibilities in $y$ and $z$ directions for fractures and $x, y, z$ directions for the matrix are determined in similar way.

\subsection{Matrix-fracture flow exchange}

By ignoring the effects of fluid and rock compressibility within matrix block, the volume of water entering the matrix block must be equal to the volume of oil recovering from it. It can be proved that the exchange rate (1.2) can be expressed as following:

$$
\left(q_{s}\right)_{w m f}=-\left(q_{s}\right)_{o m f}=-\sigma\left(\frac{k k_{r 0} k_{r w}}{\mu_{0} B_{0} k_{r w}+\mu_{w} B_{w} k_{r o}}\right)_{m}\left(p_{c m}-p_{c f}\right),
$$

where $p_{c m}, p_{c f}$ are capillary pressures in matrix and in fracture. It can be seen from (2.4) that the exchange flow depends only on the capillary effects and is proportional to the difference of capillary pressures.

Noting that the oil recovery from the matrix by gravity effects depends on Archimedes's force acting on oil volume in the matrix, it can be therefore supposed that the exchange flow rate (per volume unit) is proportional to the difference of phase average densities between matrix and fracture. Therefore, one can write that:

$$
\left(q_{s g}\right)_{w m f}=-\left(q_{s g}\right)_{o m f}=-\beta\left(\frac{k k_{r o} k_{r w}}{\mu_{0} B_{0} k_{r w}+\mu_{w} B_{w} k_{r o}}\right)_{m} \frac{\left(\rho_{m}-\rho_{f}\right) g}{c},
$$

where $\beta$ is an adjustable dimensionless parameter, $c$ is the height of matrix block, $\rho_{m}=$ $\rho_{o m} S_{o m}+\rho_{w m} S_{w m}$ is phase average density in matrix and $\rho_{f}=\rho_{o f} S_{o f}+\rho_{w f} S_{w f}$ is phase average density in fracture.

Hence, to add the gravity effects, the matrix-fracture flow exchange can be written as following:

$$
\left(q_{s}\right)_{w m f}=-\left(q_{s}\right)_{o m f}=-\left(\frac{k k_{r o} k_{r w}}{\mu_{0} B_{0} k_{r w}+\mu_{w} B_{w} k_{r_{0}}}\right)_{m}\left(\sigma\left(p_{c m}-p_{c f}\right)+\beta \frac{\left(\rho_{m}-\rho_{f}\right) g}{c}\right) .
$$

The equation (2.6) express a competition between the capillary and gravity forces. This competition is rather very complicated and has a non-linear character as it depends also on the flow of each phase. Generally, the capillary force in (2.6) is dominant initially when the fractures begin to be flooded with water because the capillary pressure difference may be then very large. However, when the matrix is flooded, this diffrence may decrease quickly and the effects of capillary effects could be negligible. For small matrix block case, the gravity effects can be negligible because the matrix block may be quickly totally flooded by the capillary effects. 


\subsection{Solution techniques}

The formulation of the dual porosity system initially has eight unknowns: pressures and saturations for oil and water in matrix and fracture system. The procedure similar to IMPES (Aziz \& Settari, 1979 [6]) reduces the number of unknowns to two:' matrix and fracture oil pressures. The system of pressure equations is larger than a single porosity formulation and has considerably different coefficients for matrix and fracture blocks. The solution of this system may require a complicated solution procedure and very big amount of CPU time.

Formula (2.6) allows to eliminate matrix pressure directly from pressure equation for fracture. As a result, only one equation for oil pressure in fracture can be obtained. So the finite-different equation system for pressure can be solved much more simply and much more faster. The SIP (Strongly Implicit Procedure) algorithm can be used (see [7] for more details).

A numerical code in FORTRAN has been developed and used to solve some examples presented below.

\section{Examples}

\subsection{Kazemi et al. Five- Spot Example}

A comparison of results of this paper with previous results of Kazemi et al. in 2D example of water injection is presented. Water is injected into one-quarter of five-spot at a rate of $200 \mathrm{STB} / \mathrm{D}\left(31.8 \mathrm{~m}^{3} / \mathrm{d}\right)$ and production of total liquid is $210 \mathrm{STB} / \mathrm{D}\left(33.4 \mathrm{~m}^{3} / \mathrm{d}\right)$. Reservoir is assumed to be fractured uniformly. The dimensions and properties are given in Table 1 and 2.

Table 1. Kazemi et al. five-spot example

\begin{tabular}{lr}
\hline Initial pressure, psia & 3959.89 \\
Thickness, ft & 30 \\
Grid dimensions & $8 \times 8$ \\
Grid spacing, $\Delta x=\Delta y, \mathrm{ft}$ & 75 \\
Fracture porosity. & 0.01 \\
Matrix porosity & 0.19 \\
Fracture effective permeability, mD & 500 \\
matrix permeability, mD & 1 \\
Matrix shape factor, sq ft & 0.08 \\
Water compressibility, vol/vol-psi & $3.0310-6$ \\
Water and Oil formation volume factor at the bubble & \\
point, RB/STB & 1.0 \\
Slope of Bo above Pb, vol/vol-psi & $3.0310-6$ \\
Fracture compressibility, vol/vol-psi & 0.5 \\
Water viscosity, cp & 2 \\
Oil viscosity, cp & 0.4444 \\
Water density, psi/ft & 0.3611 \\
Oil density, psi/ft & 0.000103093 \\
\hline
\end{tabular}


Table 2. Relative permeability and capillary data for Kazemi et al. example

\begin{tabular}{|c|c|c|c|c|c|c|}
\hline$S_{w}$ & $k_{r w f}$ & $k_{\text {rof }}$ & $P_{\text {cowf }}(p s i)$ & $k_{\text {rwm }}$ & $k_{\text {rom }}$ & $P_{\text {cowm }}(p s i)$ \\
\hline 0.0 & 0.0 & 1.0 & 4.0 & - & - & - \\
\hline 0.1 & 0.05 & 0.770 & 1.85 & - & - & - \\
\hline 0.2 & 0.11 & 0.587 & 0.90 & - & - & - \\
\hline 0.25 & 0.145 & 0.519 & 0.725 & 0.0 & 0.92 & 4.0 \\
\hline 0.3 & 0.180 & 0.450 & 0.55 & 0.02 & 0.705 & 2.95 \\
\hline 0.4 & 0.260 & 0.330 & 0.4 & 0.055 & 0.420 & 1.65 \\
\hline 0.5 & 0.355 & 0.240 & 0.29 & 0.1 & 0.240 & 0.85 \\
\hline 0.6 & 0.475 & 0.173 & 0.20 & 0.145 & 0.11 & 0.3 \\
\hline 0.7 & 0.585 & 0.102 & 0.16 & 0.2 & 0.0 & 0.0 \\
\hline 0.8 & 0.715 & 0.057 & 0.11 & - & - & - \\
\hline 0.9 & 0.850 & 0.021 & 0.05 & - & - & - \\
\hline 1.0 & 1.0 & 0.0 & 0.0 & - & - & - \\
\hline
\end{tabular}

For this example, water breakthrough occurred after approximately 30 days, but water production remained relatively low for 500 days because of imbibition of water into matrix rock and flow of oil into fracture system.

A comparison of water/oil ratio (WOR) from this work and that calculated by Kazemi et al. is shown in Fig. 1. The agreement is quite good. By the end of 1200 days, water saturation in the fracture at the injection cell was 0.97 and water saturation in the matrix was 0.58 . Similar values were obtained by Kazemi et al. [2].

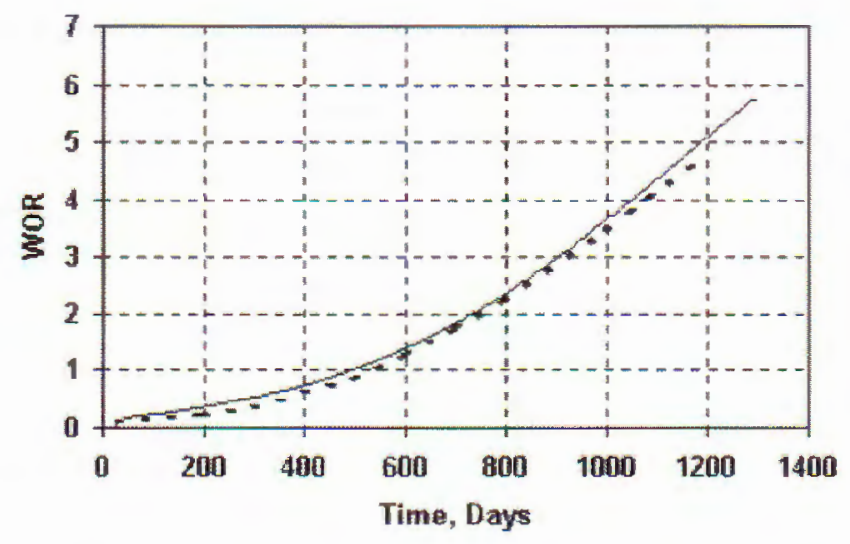

- . - Kazemi el al. results _ This work resulls

Fig. 1. Variation of water/oil ratio (WOR) in Kazemi's five-spot example

This example shows that the model works well with a "classical example" without gravity effects. The next two examples will show that our simple model for gravity effects can produce the results comparable to more complicated models such as that of Quandalle \& Sabathier [5] and that of Kazemi \& Gilman [3]. 


\subsection{Dual-Porosity Reliability Tests of Quandalle and Sabathier}

The effects of gravity forces in oil recovery from matrix was tested with an example given by Quandalle and Sabathier [5]. The column of eight $30 \mathrm{ft}$ cubic matrix blocks surrounded by fractures is simulated. Matrix porosity and absolute permeability are $19.8 \%$ and $1 \mathrm{mD}$, while those of fracture are $1 \%$ and $666 \mathrm{mD}$ respectively. The column is initially oil saturated, water is injected in the fractures at the bottom and an equivalent volume of liquid is produced at the top. Rock and fluid properties are described in Fig. 2.
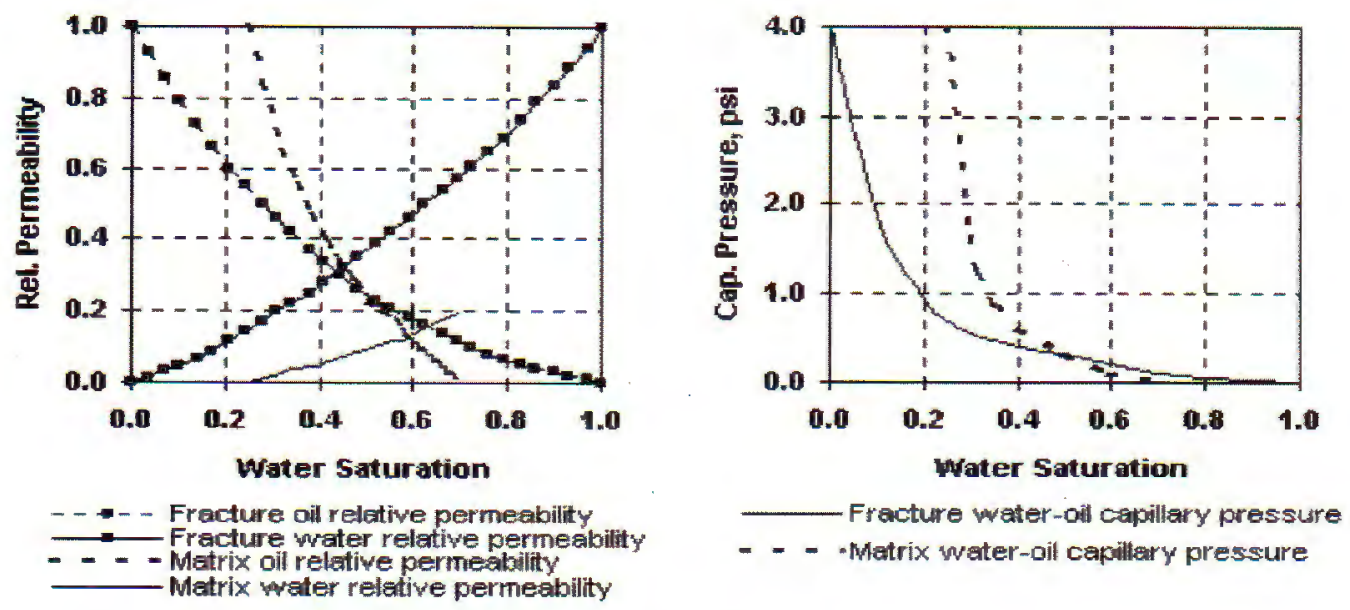

Fig. 2. Rock and fluid properties in Quandalle and Sabathier dual porosity tests

The cumulative oil production versus time for two cases with gravity effects and without gravity effects (with $\beta=1$ ) are reported in Fig. 3. It can be noted that the gravity effects are not negligible. They are more significant when injected water volume is large. The comparison with results of Quandalle and Sabathier shows also a good agreement.
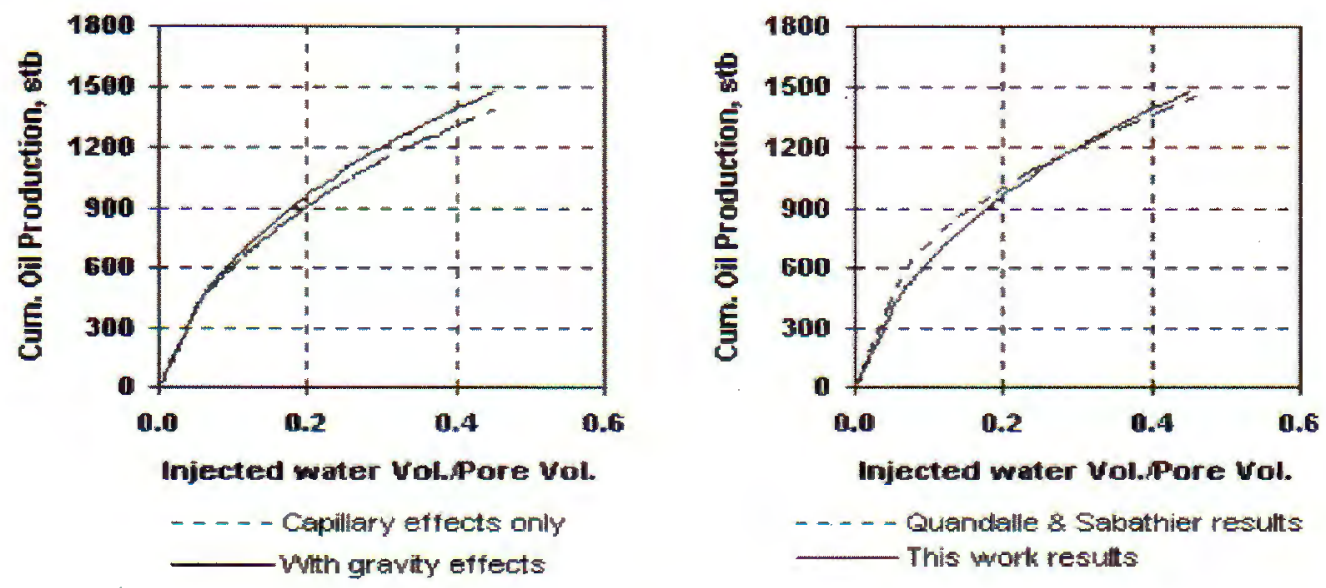

Fig. 3. Cumulative oil production as function of injected water volume in

Quandalle and Sabathier dual porosity tests : (left) gravity effects, (right) comparison with Quandalle \& Sabathier model with gravity 


\subsection{Field-scale three-dimensional Simulation}

The numerical code has been used for simulation of a large reservoir in real condition. The results was compared with field data and the results of a commercial simulator IMEX of CMG, Canada, for which the gravity effects is taken into account by Kazemi \& Gilman's [3] or Gilman's [4] approach. The reservoir of dimension $5400 \mathrm{~m} \times 4000 \mathrm{~m} \times 1000 \mathrm{~m}$ is divided into a grid of $54 \times 40 \times 16$ cells. The bottom of the reservoir is initially filled with water of the height of $200 \mathrm{~m}$. The reservoir is exploited by five wells for a period of 3 years.
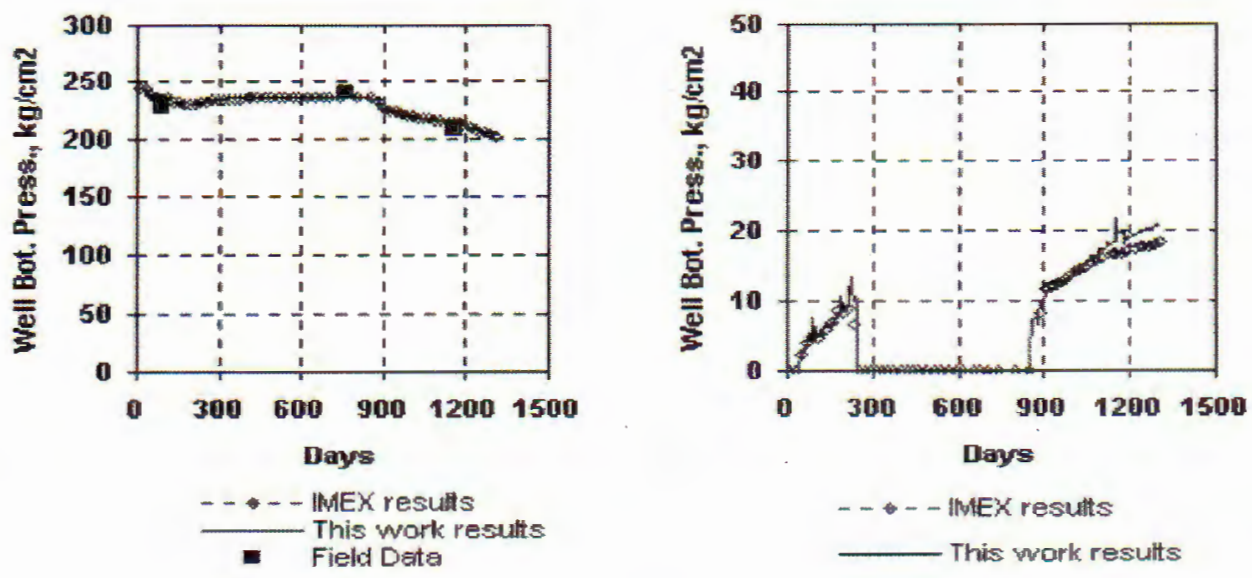

Fig. 4. Variation of pressure and WOR for Well Nr 1 in field-scale problem
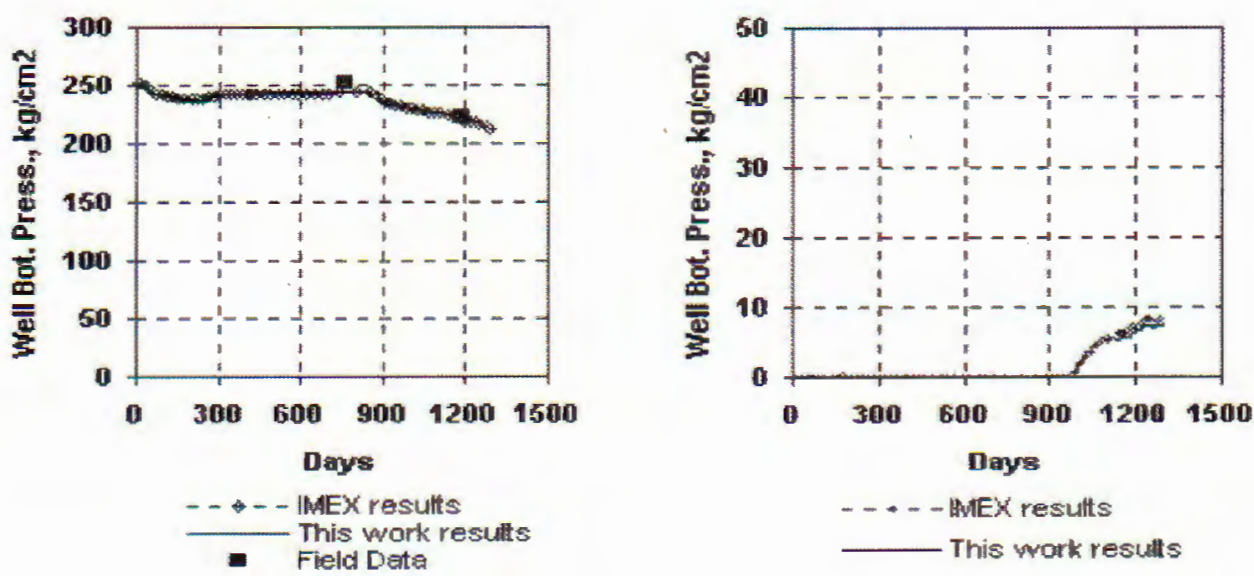

Fig. 5. Variation of pressure and WOR for Well Nr 2 in field-scale problem

Some examples of calculation results are shown in Fig. 4 and Fig. 5. Because of high fracture permeability, water breakthrough occurs very soon after approximately 40 days in the well $\mathrm{Nr}$ 1. The results of the code match very good with the results of IMEX for both well bottom pressure and water/oil ratio (WOR). Very few field data were available, however it can be seen that the simulation results show a good agreement for pressures (for example, see Fig. 4 and Fig. 5). 


\section{Conclusions}

This paper presents the development of 3D, two-phase (water/oil) model for simulating the flow of fluids in a naturally fractured reservoir. The matrix/fracture transfer function for two-phase flow is based on an extension of the equation developed Kazemi et al. [2] to account for capillary pressure and gravity effects.

The solution algorithm based on this approach is relatively simple and stable. The example problems demonstrate a good agreement with previous results and a significant effect of the gravity force on the predicted performance of fractured reservoirs. The model can be used for field-scale simulation of oil/water flow and gives the good results by comparison with the field data and the results of a commercial reservoir simulator.

Acknowlegement. The authors express their gratitude towards the personnel of Department of Drilling and Exploitation of NIPI-Vietsovpetro for providing the data for field-scale problem. This paper is completed with partly financial support from the National Basic Research Program in Natural Sciences.

\section{References}

1. Barenblatt G. I., Zeltov I. P. and Kochina I. N., Basic concepts in the theory of seepage of homogeneous liquids in fissure rocks, Prikl. Mat. Mech. 24 (1960).

2. Kazemi H. et al., Numerical Jimulation of Water-oil flow in naturally fractured reservoir, Soc. Petroleum Eng. J., 1976.

3. Kazemi H. and Gillman J., Improvements in simulation of naturally fractured reservoirs, Soc. Petroleum Eng. J. 23 (1983).

4. Gillman J., An efficient finite-difference method for simulating phase segregation in the matrix block in double-porosity reservoirs, Soc. Petroleum Eng. J. 26 (1986).

5. Quandalle P., Sabathier J. C., Typical Features of New Multipurpose Reservoir Simulator, SPE paper 16007 at Ninth SPE Symposium on Reservoirs Simulation, Dallas, Texas, 1987.

6. Khalid Aziz, Antonin Settari, Petroleum Reservoir Simulation. ASP, London, 1979.

7. Duong Ngoc Hai et al., Report of Research Project "Study on the Methods and Simulators for Multi-Phase Flow in Oil Reservoirs in Vietnam", Institute of Mechanics, Hanoi, 2000.

Received August 8, 2003

\section{MÔ HÌNH SỐ TÍNH DÒNG CHẢY DẦU-NƯỚC TRONG VİA NỨT NÊ TỰ NHIÊN}

Bài báo trình bày việc xây dựng mô hình 2 pha, 3 chiều mô phỏng dòng chảy dầu-nước trong vìa nứt nè tự nhiên. Mô hình dựa trên tiếp cận 2 độ rỗng. Dòng chảy chính trong vỉa là dòng chảy trong hệ thống nứt né với sự trao đổi chất lờng giữa hệ thống nứt nè và các khối đá chứa dầu-matrix. Công thức mới xác định lượng trao đổi chất lơng giữa nứt nẻ và matrix được đề xuất bằng cách mở rộng công thức phát triển bởi Kazemi để tính đến các hiệu ứng trọng trường. Công thức này cho phép loại trừ áp suất matrix trong phương trình áp suất nứt né và làm đơn giản hóa thuật giải.

Một sối ví dụ tính toán được trình bày để kiểm chứng mô hình. Đó là sự so sánh kết quả của bài báo với các kết quả đã công bố trước kia, chì ra hiệu ứng trọng trường và khả năng ứng dụng của mô hình vào bài toán thực tế. 